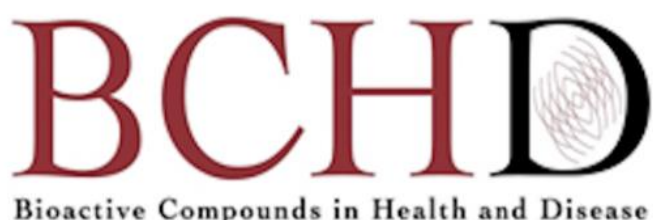

\title{
Hibiscus rosa sinensis L. anthocyanins prevent lipid peroxidation and improve antioxidant status in the liver of streptozotocin-induced diabetic rats
}

\author{
Velappan Nair Saralakumari Kalpana ${ }^{1}$, Jincy Mary ${ }^{1}$, Saraswathy Mini ${ }^{1 *}$, Neelakanta Pillai \\ Padmakumari Soumya ${ }^{1}$, Sukanta Mondal ${ }^{2}$
}

\begin{abstract}
${ }^{1}$ Department of Biochemistry, University of Kerala, Karyavattom Campus, Thiruvananthapuram, India; ${ }^{2}$ ICARNational Institute of Animal Nutrition and Physiology, Bengaluru, India

*Corresponding Author: Dr. Saraswathy Mini, Professor, Department of Biochemistry, University of Kerala, Karyavattom Campus, Thiruvananthapuram, India

Submission Date: September 7th 2021 ; Acceptance Date: October 22 ${ }^{\text {nd }}, 2021$; Publication Date: October $28^{\text {th }}, 2021$

Please cite this as: Kalpana V.S., Mary J., Mini S., Soumya N.P., Mondal S. Hibiscus rosa sinensis L. anthocyanins prevent lipid peroxidation and improve antioxidant status in the liver of streptozotocin-induced diabetic rats. Bioactive Compounds in Health and Disease 2021; 4(10): 240-255. DOI: https://www.doi.org/10.31989/bchd.v4i10.842
\end{abstract}

\section{ABSTRACT:}

Background: Hyperglycemia and oxidative stress are hallmarks of diabetes mellitus (DM). Excessive oxidative stress is implicated in diabetic pathogenesis when endogenous antioxidants are defective.

Objective: The present study evaluates the effects of anthocyanins present in the petals of Hibiscus rosa- sinensis on oxidative stress and antioxidant status in streptozotocin-induced diabetic rats.

Materials and methods: Diabetes was induced in male Sprague-Dawley rats by a single intraperitoneal injection $(30 \mathrm{mg} / \mathrm{kg})$ of streptozotocin. Hibiscus rosa sinensis anthocyanins $(\mathrm{HA})$ extract ( $50 \mathrm{mg} / \mathrm{kg}$ body weight) orally administered to diabetic rats for 30 days. Results compared with diabetic rats provided with the standard drug metformin (150 $\mathrm{mg} / \mathrm{kg}$ body weight).

Results: Altered levels of glucose, glycated hemoglobin, toxicity markers and lipid profile in serum were significantly modulated upon the administration of HA in diabetic rats. A supplementation of HA to diabetic rats reduced 
oxidative stress, as well as increased the levels of antioxidant enzymes in the liver. The present study demonstrates that HA has a protective effect on diabetic rats

Conclusion: The present study indicates that Hibiscus anthocyanin supplementation could protect diabetic rats' livers by protecting the hepatocytes from oxidative stress and increasing the antioxidant enzymes' activity.

Keywords: Diabetes mellitus, Hibiscus rosa sinensis anthocyanins, Oxidative stress

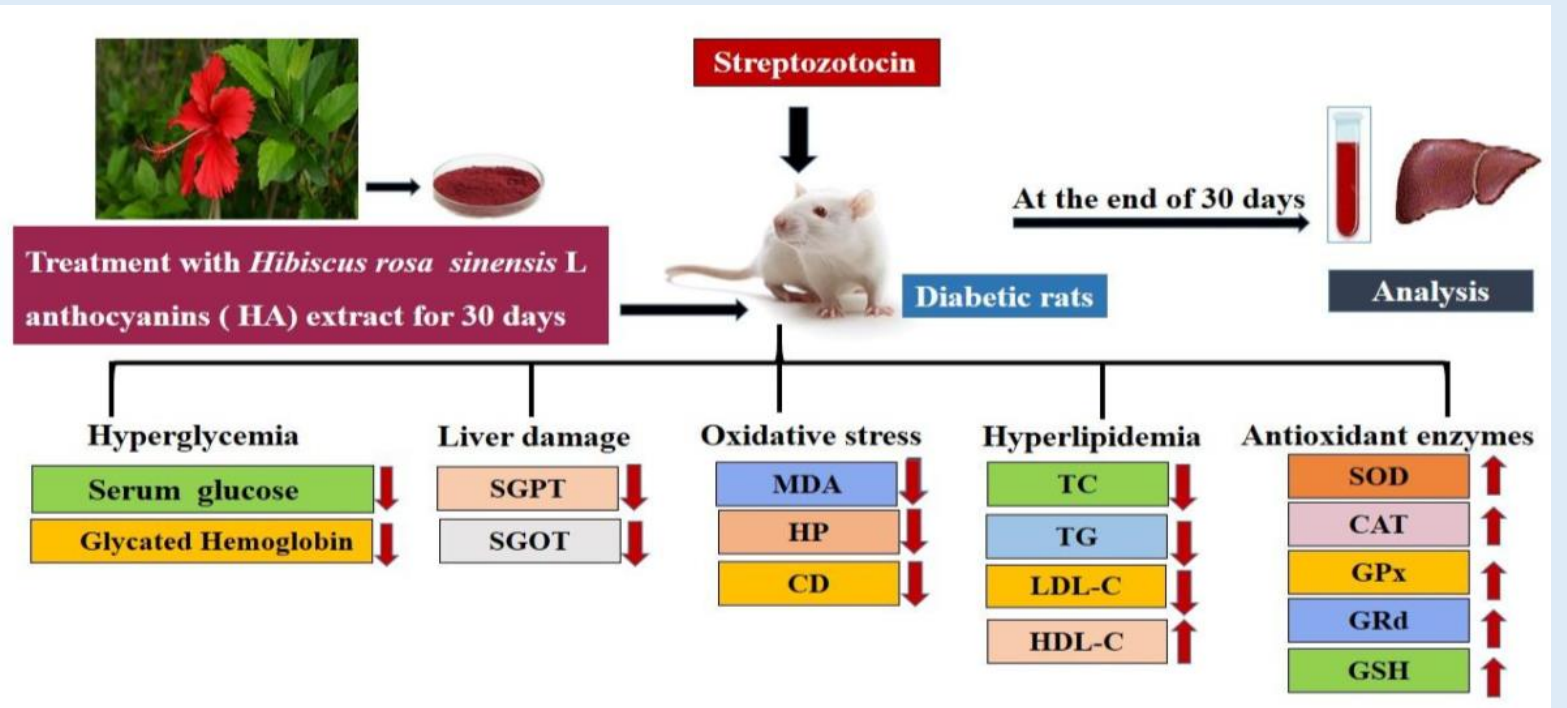

CFFC 2021. This is an Open Access article distributed under the terms of the Creative Commons Attribution 4.0 License (http://creativecommons.org/licenses/by/4.0)

\section{INTRODUCTION}

Diabetes mellitus (DM) is a group of metabolic disorders characterized by hyperglycemia, caused by impaired insulin production by pancreatic beta-cells and insulin resistance in peripheral tissues [1]. Oxidative stress is the imbalance between the generation of free radicals and the antioxidant defense system [2]. Persistent hyperglycemia in diabetes results in the production of reactive oxygen species (ROS) through the activation of several pathways like glyceraldehyde autoxidation, methylglyoxal glycation, protein kinase $C$ (PKC) activation, hexosamine pathways, and oxidative phosphorylation [3]. The liver is one of the tissues susceptible to oxidative stress. Studies have shown that the main sources of free radicals in hepatic tissue are mitochondria and cytochrome P450 enzymes. Previous studies suggest that oxidative stress contributes to hepatic complications [4]. Generally, oxidative stress leads to oxidation and damage of macromolecules involved in energy production (such as proteins, lipids, and enzymes) and is involved in the cellular injury, energy depletion, and acceleration of cell death through apoptosis and necrosis. Studies have demonstrated that oxidative stress increases lipid peroxidation and decreases antioxidant activity [5]. Superoxide dismutase (SOD), glutathione peroxidase $(\mathrm{GPx})$, catalase (CAT), and reduced 
glutathione (GSH) are antioxidants capable of scavenging free radicals by breaking down ROS [6]. Polyphenols are bioactive compounds in plants, fruits, and vegetables with antioxidant properties that have been shown to prevent diabetic complications caused by oxidative stress. [7].

Hibiscus rosa sinensis Linn. (Malvaceae) is a shrub commonly found in the tropics of India. The plant is reported to possess hypoglycemic, cardioprotective, antitumor, anti-fertility, antiinflammatory, hair growth-promoting, and antioxidant properties [8]. It is broadly used as an ingredient in herbal teas; its beneficial effects are attributed to the antioxidant phenolic compounds. The previous studies conducted in our lab revealed the protective role of flavonoid-rich ethyl acetate fraction of Hibiscus rosa sinensis flower petals in modulating glucose homeostasis and diabetic stress signaling pathways [9]. The red pigments in red flowers of the Hibiscus are the anthocyanins and have been widely used as coloring agents.

Anthocyanins (ACs) are water-soluble polyphenolic pigments and are referred to as flavonoids [10]. Anthocyanins are responsible for redorange to blue-violet colors in various plants, especially purple cabbage, purple grapes, blueberries, cherries, black rice, flowers, fruits, and vegetables [11]. Anthocyanins are found as aglycon derivatives called anthocyanidins. Anthocyanidins, viz., cyanidin, delphinidin, malvidin, peonidin, pelargonidin, and petunidin, are predominantly found in nature [12]. The in vitro, in vivo, and clinical trial studies identified ACs as potent antioxidative compounds capable of preventing the progression of several chronic degenerative diseases related to ageing, oxidative stress, and inflammation, such as diabetes, cardiovascular diseases, or neurodegenerative diseases [13]. Animal studies showed that purified anthocyanins and foods containing anthocyanins regulated glucose metabolism, enhanced insulin sensitivity, and improved $\beta$ cell dysfunction in type 2 diabetes. Consumption of anthocyanins and anthocyanin-rich fruit was associated with a lower risk of type 2 diabetes in large cohort studies [14].

The present study investigates the beneficial protective effect of the anthocyanins present in the Hibiscus rosa sinensis flower petals on oxidative stress and antioxidant status in the hepatic tissue of streptozotocin-induced diabetic rats.

\section{MATERIALS AND METHODS}

Chemicals: All Chemicals for the current study were purchased from SIGMA ALDRICH (St. Louis, MO, USA), MERCK Chemical Company (Darmstadt, Germany), and Sisco Research Laboratories (Mumbai, India).

\section{Preparation of Anthocyanin-rich extract from} Hibiscus rosa sinensis flower petals: Hibiscus rosa sinensis flowers were collected from Trivandrum, India. Authentication was done by Dr. G. Valsala Devi, Curator, Department of Botany, and the University of Kerala. For further reference, a voucher specimen (Voucher No. KUBH-5845) has been deposited in the herbarium, Department of Botany, the University of Kerala. The petals were shade dried and powdered, $10 \mathrm{~g}$ of the petal powder weighed was soaked in 200 $\mathrm{mL}$ acidified methanol $(0.1 \% \mathrm{HCl}(\mathrm{v} / \mathrm{v})$ in methanol) for 3 hours at room temperature in darkness [15]. The mixture was filtered in a Buchner funnel, and the remaining solids were washed with $0.1 \% \mathrm{HCl}$ in methanol until a clear solution was obtained. The combined filtrates were dried using a rotary evaporator at $55^{\circ} \mathrm{C}$. The dried extract was dissolved in water and used for the present study. Figure 1 shows an image of the Hibiscus rosa sinensis flower. 


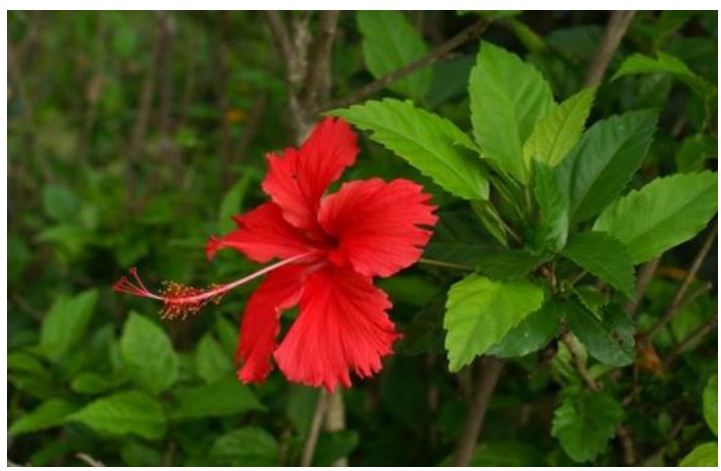

Figure 1: Hibiscus rosa sinensis flower

Detection of Total Anthocyanin content: Anthocyanin analysis was performed using a UVvisible spectrophotometric $\mathrm{pH}$ differential method [16-17].

Experimental animals: Male albino rats (SpragueDawley) of body weight $200-250$ g were used for the study. They were provided with Laboratory chow (Hindustan Lever Lab diet) and water ad libitum throughout the experimental period. The rats were housed in polypropylene cages in a room with temperature maintained at $26 \pm 1^{\circ} \mathrm{C}$ and a 12 hour light and dark cycle. The institutional animal ethics committee approved all experimental protocols (IAEC-KU-11/2013-14- BC- SM (19).

Induction of experimental diabetes: Diabetes was induced in rats by a single intraperitoneal injection of freshly prepared STZ at a $30 \mathrm{mg} / \mathrm{kg}$ body weight dose in $0.1 \mathrm{M}$ citrate buffer $(\mathrm{pH} 4.5)$ [18]. The animals were allowed to drink $5 \%$ glucose solution overnight to overcome the drug-induced hypoglycemia. The animals with blood glucose levels between $200 \mathrm{mg} / \mathrm{dL}$ and $400 \mathrm{mg} / \mathrm{dL}$ are considered diabetic.

Experimental design: The oral toxicity study was performed as per OECD guidelines 420. It was previously performed in our laboratory using three different doses of HA (50 mg/ kg body weight, 100 $\mathrm{mg} / \mathrm{kg}$ body weight, and $200 \mathrm{mg} / \mathrm{kg}$ body weight). The extract at an optimal dose of $50 \mathrm{mg} / \mathrm{kg}$ body weight was effective and safe compared with the other two doses $(100 \mathrm{mg} / \mathrm{kg}$ body weight and $200 \mathrm{mg} / \mathrm{kg}$ body weight). Therefore, the optimum dose of HA was used for the present study. Analyses of the Hibiscus rosa sinensis flower petals extract revealed the presence of $0.35 \mathrm{gm} \%$ anthocyanins. Diabetes was induced in rats by a single intraperitoneal injection of freshly prepared STZ at a dose of $30 \mathrm{mg} / \mathrm{kg}$ body weight. Diabetic rats were supplemented with Hibiscus anthocyanins $(50 \mathrm{mg} / \mathrm{kg}$ body weight) by gastric intubation for 30 days. The experimental animals were divided into five groups of six rats each. The effect was compared with the antidiabetic drug Metformin.

Group 1: Normal control rats (N)

Group 2: Normal rats treated with HA $(50 \mathrm{mg} / \mathrm{Kg}$ body weight) $(\mathrm{N}+\mathrm{HA})$

Group 3: Diabetic control rats (D)

Group 4: Diabetic rats treated with HA $(50 \mathrm{mg} / \mathrm{Kg}$ body weight) $(D+H A)$

Group 5: Diabetic rats treated with Metformin (150 $\mathrm{mg} / \mathrm{Kg}$ body weight) (D+M)

During the experimental period, the body weight and blood glucose of the rats were monitored at definite intervals. Dosage of the extract and standard drugs were maintained in accordance with the change in body weight of the rats throughout the study period. After 30 days, the rats were sacrificed, and blood and liver were collected for various biochemical analyses.

Biochemical parameters: Serum glucose was estimated by the glucose oxidase method described by [19]. The amount of glycated hemoglobin (HbA1c) was quantified by using the HbAlc kit (Beacon Diagnostics Pvt. Ltd). Total cholesterol (TC), 
Triglycerides (TG), High-density lipoprotein cholesterol (HDL-C), and Low-density lipoprotein cholesterol (LDL-C) were determined using AGAPPE diagnostics kits (AGAPPE Diagnostics Limited, Ernakulam, Kerala). Serum Glutamate Pyruvate Transaminase (SGPT) and Serum Glutamate Oxaloacetate Transaminase (SGOT) were assayed using the enzyme kit from CML Biotech (P) Ltd, Ernakulam, India, described by [20]. The protocol of [21] determined the activity of catalase (CAT), and the superoxide dismutase (SOD) activity was measured by the method of [22]. The protocol of [23] evaluated the activity of Glutathione peroxidase (GPx), glutathione reductase (GRd) activity by the procedure of [24]. The glutathione content (GSH) was analyzed by the procedure given by [25]. Thiobarbituric acid reactive substances (TBARS) were estimated by the method of [26]. Hydroperoxides (HP) and conjugated dienes (CD) were estimated by the method of [27]. Protein was estimated according to the method of [28] respectively.

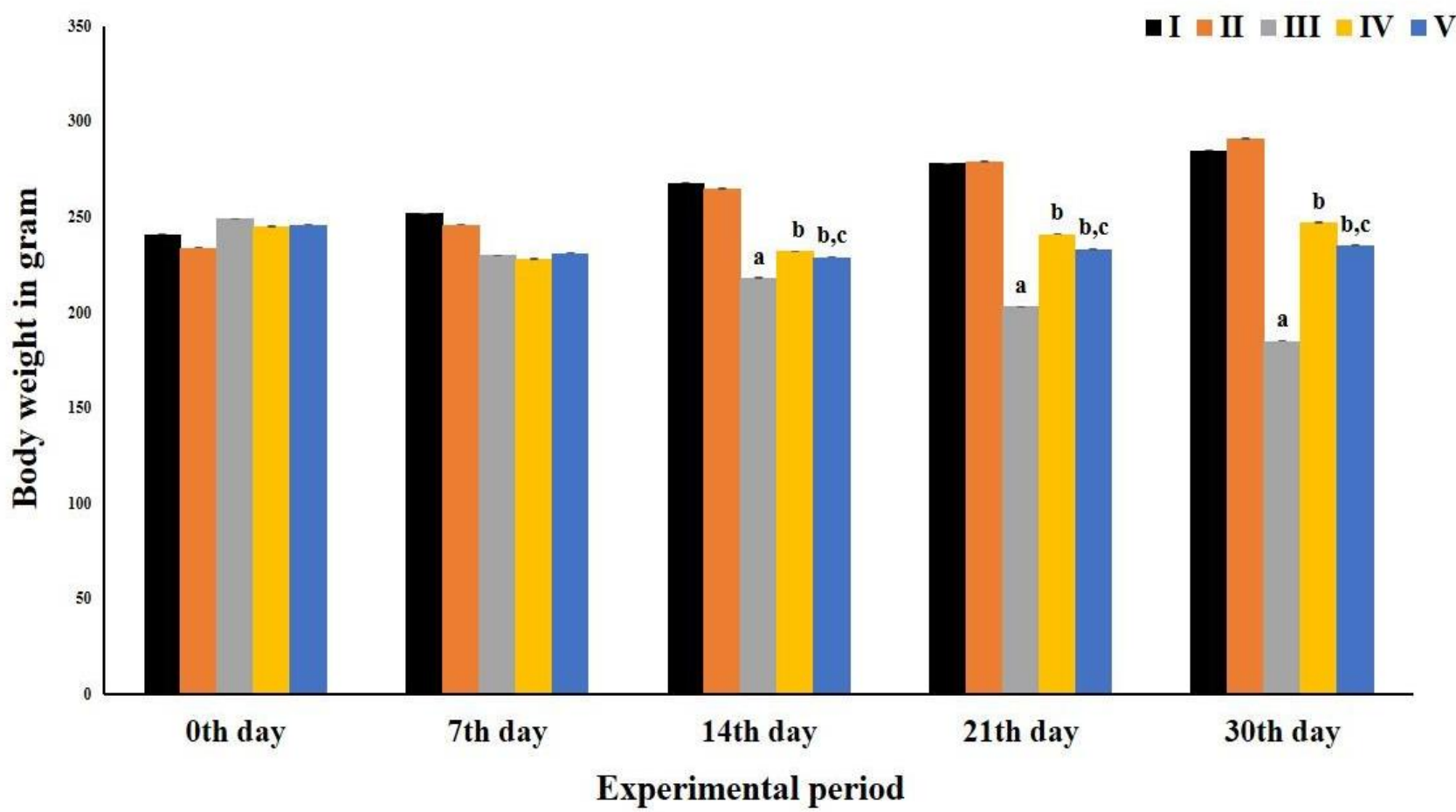

Statistical analysis: Values were expressed as mean \pm SD. Statistical analyses were performed by one-way ANOVA using SPSS version 17 (SPSS, Inc., Chicago, IL, USA). Duncan's post hoc multiple-comparison tests were used to determine significant differences among groups. $p<0.05$ was considered to be significant.

\section{RESULTS}

Total Anthocyanin content: Anthocyanin analyses of the Hibiscus rosa sinensis flower petals extract revealed the presence of $0.35 \mathrm{gm} \%$ anthocyanins.

Change in body weight: In the present study, the average body weight of the rats was uniform at the beginning of the experiment. The body weights of rats were significantly diminished in STZ induced diabetic control rats when compared to normal control rats. However, HA or metformin supplementation significantly improved the bodyweight of diabetic rats when compared to diabetic control rats (Fig 2). 
Values are expressed as mean \pm SD $(n=6)$. Group I: Normal control(N); Group II: Normal rats given $50 \mathrm{mg}$ Hibiscus anthocyanin (HA) / kg body weight of rats (N+HA); Group III: Diabetic control (D); Group IV: Diabetic rats given $50 \mathrm{mg}$ Hibiscus anthocyanin $(\mathrm{HA}) / \mathrm{kg}$ body weight of rats $(\mathrm{D}+\mathrm{HA})$; V: Diabetic rats given $150 \mathrm{mg}$ metformin/kg body weight of rats (D+M). 'a' indicates values significantly different from normal control groups. 'b' indicates values significantly differ from diabetic groups. ' $c$ ' indicates

A

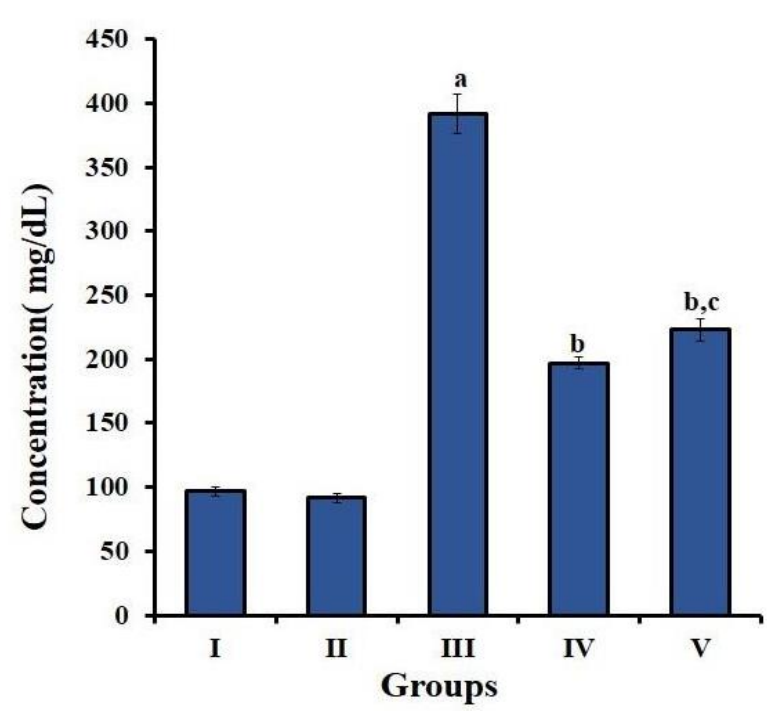

values are significantly different from HA treated groups. Significance accepted at $p<0.05$.

Serum glucose and Glycated hemoglobin (HbA1c): Serum glucose (Figure 3A) and HbA1c levels (Figure 3B) were significantly elevated in diabetic control rats compared to normal control rats. The oral administration of $\mathrm{HA}$ or metformin significantly reduced serum glucose and $\mathrm{HbA} 1 \mathrm{c}$ levels compared to diabetic control rats. However, oral administration of $\mathrm{HA}$ to normal rats didn't show any significant deviation in serum glucose and glycated hemoglobin.

B

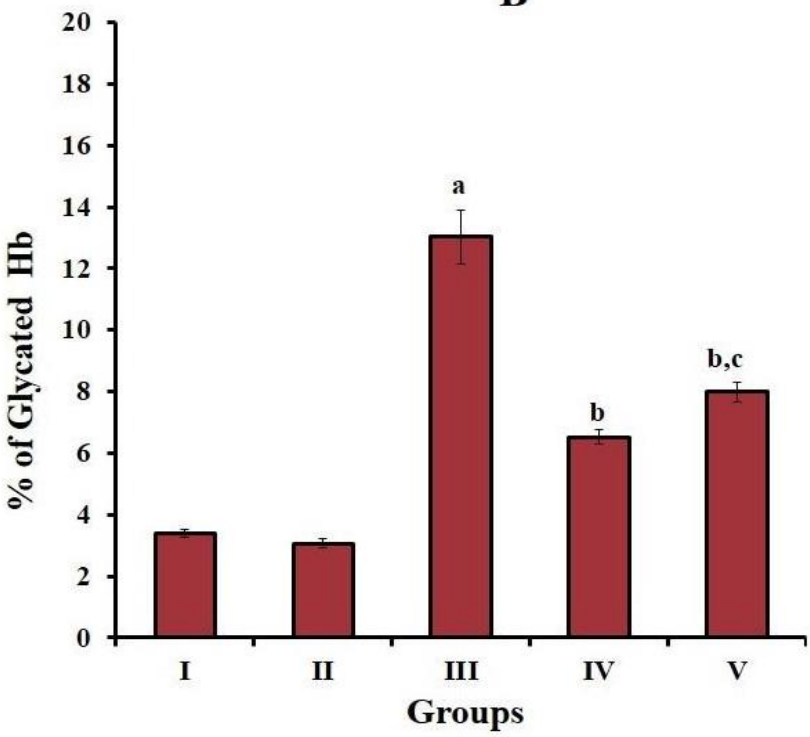

Figure 3. Serum glucose and Glycated hemoglobin

A) Serum glucose. B) Glycated hemoglobin. Values are expressed as mean \pm SD $(n=6)$. Group I: Normal control(N); Group II: Normal rats given 50 mg Hibiscus anthocyanin (HA) /kg body weight of rats (N+HA); Group III: Diabetic control (D); Group IV: Diabetic rats given $50 \mathrm{mg}$ Hibiscus anthocyanin (HA)/kg body weight of rats (D+HA); V: Diabetic rats given $150 \mathrm{mg}$ metformin/kg body weight of rats $(D+M)$. 'a' indicates values significantly different from normal control groups. 'b' indicates values significantly different from diabetic groups. ' $c$ ' indicates values are significantly different from HA treated groups. Significance accepted at $p<0.05$.

Serum toxicity markers: Liver toxicity markers were assayed to assess the hepatic injury. The activities of serum glutamate pyruvate transaminase (SGPT) and serum glutamate oxaloacetate transaminase (SGOT) were significantly raised in diabetic control rats compared to normal control rats. Supplementation of HA or metformin to diabetic rats significantly decreased the SGPT and SGOT activities compared with the diabetic control rats (Table 1). 
Table 1: Toxicity markers in serum

\begin{tabular}{|c|c|c|}
\hline GROUPS & \multicolumn{1}{|l|}{ SGPT (U/L) } & $33.43 \pm 4.85$ \\
\hline I & $40.03 \pm 3.83$ & $29.33 \pm 3.88^{\mathrm{a}}$ \\
\hline II & $35.57 \pm 3.07^{\mathrm{a}}$ & $48.26 \pm 4.60^{\mathrm{a}}$ \\
\hline III & $64.84 \pm 6.21^{\mathrm{a}}$ & $38.70 \pm 3.70^{\mathrm{b}}$ \\
\hline IV & $47.09 \pm 4.51^{\mathrm{b}}$ & $37.44 \pm 3.50^{\mathrm{b}}$ \\
\hline V & $48.46 \pm 4.64^{\mathrm{b}}$ & \\
\hline
\end{tabular}

Toxicity markers in serum: Values are expressed as mean \pm SD $(n=6)$. Group I: Normal control(N); Group II: Normal rats given $50 \mathrm{mg}$ Hibiscus anthocyanin (HA) /kg body weight of rats ( $\mathrm{N}+\mathrm{HA})$; Group III: Diabetic control (D); Group IV: Diabetic rats given $50 \mathrm{mg}$ Hibiscus anthocyanin (HA)/kg body weight of rats (D+HA); V: Diabetic rats given $150 \mathrm{mg}$ metformin/kg body weight of rats $(D+M)$. 'a' indicates values significantly different from normal control groups. 'b'

A

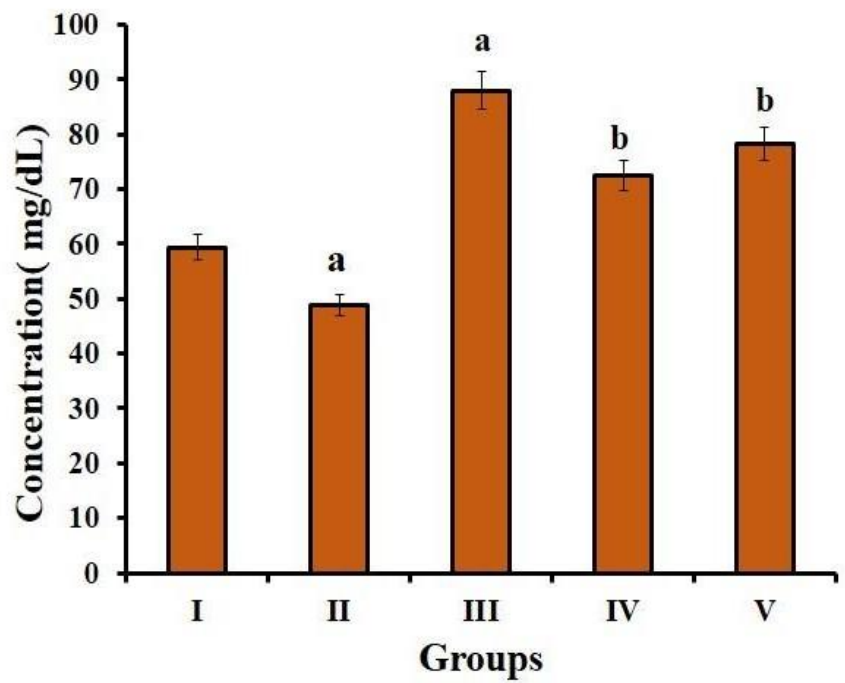

Figure 4. Serum Total cholesterol and Triglycerides indicates values significantly different from diabetic groups. Significance accepted at $p<0.05$.

Total cholesterol (TC) and Triglycerides (TG) in serum: The concentrations of total cholesterol (Figure 4A) and triglycerides (Figure 4B) in serum were increased significantly in diabetic control rats when compared to normal rats. HA or metformin supplementation reduces the concentrations of TC and TG in diabetic rats when compared to untreated diabetic rats.

B

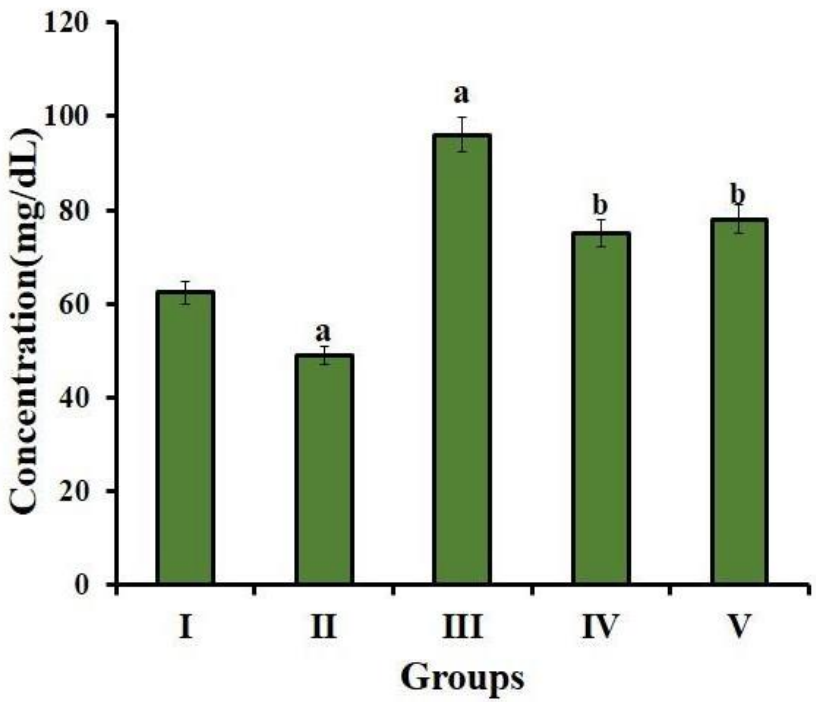


A) Total cholesterol B) Triglycerides. Values are expressed as mean $\pm S D(n=6)$. Group I: Normal control(N); Group II: Normal rats given $50 \mathrm{mg}$ Hibiscus anthocyanin (HA) / kg body weight of rats (N+HA); Group III: Diabetic control (D); Group IV: Diabetic rats given 50 mg Hibiscus anthocyanin (HA)/kg body weight of rats $(\mathrm{D}+\mathrm{HA}) ; \mathrm{V}$ : Diabetic rats given $150 \mathrm{mg}$ metformin/kg body weight of rats $(D+M)$. 'a' indicates values significantly different from normal control groups. 'b' indicates values significantly different from diabetic groups.

A

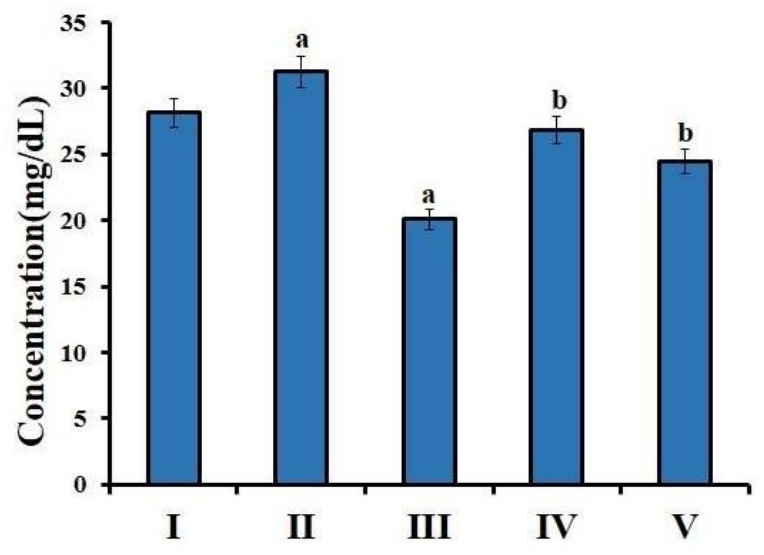

Groups
High-density lipoprotein (HDL) and Low-density lipoprotein (LDL) in serum: The good cholesterol HDL was significantly decreased in diabetic control rats when compared to normal rats. HA or metformin administration significantly increased the level of HDL in diabetic rats (Figure 5A). The bad cholesterol, LDL in serum (Figure 5B), was increased significantly in diabetic rats compared to normal rats. But HA or metformin supplementation reduces the level of LDL in diabetic rats when compared to untreated diabetic rats.

\section{B}

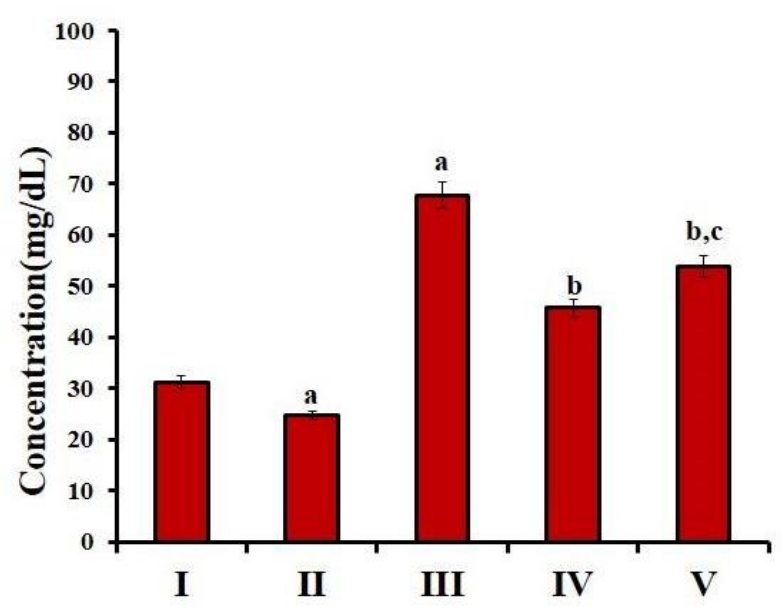

Groups

Figure 5. $\mathrm{HDL}$ in serum and LDL in serum

A) HDL in serum B) LDL in serum. Values are expressed as mean \pm SD $(n=6)$. Group I: Normal control(N); Group II: Normal rats given 50 mg Hibiscus anthocyanin (HA) /kg body weight of rats (N+HA); Group III: Diabetic control (D); Group IV: Diabetic rats given $50 \mathrm{mg}$ Hibiscus anthocyanin (HA)/kg body weight of rats (D+HA); V: Diabetic rats given $150 \mathrm{mg}$ metformin/kg body weight of rats $(D+M)$. ' $a$ ' indicates values significantly different from normal control groups. 'b' indicates values significantly different from diabetic groups. ' $c$ ' indicates values are significantly different from HA treated groups. Significance accepted at $p<0.05$.

Hepatic antioxidant enzyme activities: The activities of antioxidant enzymes superoxide dismutase (SOD), catalase (CAT), glutathione peroxidase (GPx), and glutathione reductase (GRd) were significantly diminished in diabetic control groups as compared to normal control groups. While the inclusion of HA or metformin significantly enhanced the activities of antioxidant enzymes in the liver of diabetic rats (Table 2). 
Table 2: Hepatic antioxidant enzyme activities:

\begin{tabular}{|c|c|c|c|c|}
\hline GROUPS & $\begin{array}{c}\text { CAT } \\
\left(\mathbf{1 0} \mathbf{3}^{-3} \mathbf{U} / \mathrm{mg} \text { protein) }\right.\end{array}$ & $\begin{array}{c}\text { GPx } \\
\text { (U/mg protein) }\end{array}$ & $\begin{array}{c}\text { GRd } \\
\text { (U/mg protein) }\end{array}$ & $\begin{array}{c}\text { SOD } \\
\text { (U/mg protein) }\end{array}$ \\
\hline I & $6.04 \pm 0.57$ & $30.9 \pm 2.96$ & $21.4 \pm 2.05$ & $4.48 \pm 0.43$ \\
\hline II & $7.70 \pm 0.73^{\mathrm{a}}$ & $31.7 \pm 3.04$ & $25.1 \pm 2.41^{\mathrm{a}}$ & $6.01 \pm 0.57^{\mathrm{a}}$ \\
\hline III & $3.11 \pm 0.30^{\mathrm{a}}$ & $18.6 \pm 1.78^{\mathrm{a}}$ & $13.6 \pm 1.30^{\mathrm{a}}$ & $3.15 \pm 0.30^{\mathrm{a}}$ \\
\hline IV & $4.97 \pm 0.47^{\mathrm{b}}$ & $27.1 \pm 2.60^{\mathrm{b}}$ & $20.1 \pm 1.90^{\mathrm{b}}$ & $4.19 \pm 0.40^{\mathrm{b}}$ \\
\hline V & $3.90 \pm 0.37^{\mathrm{b}, \mathrm{c}}$ & $23.1 \pm 2.20^{\mathrm{b}, \mathrm{c}}$ & $17.2 \pm 1.65^{\mathrm{b}, \mathrm{c}}$ & $3.70 \pm 0.36^{\mathrm{b}}$ \\
\hline
\end{tabular}

Values are expressed as mean \pm SD $(n=6)$. Group I: Normal control(N); Group II: Normal rats given 50 mg Hibiscus anthocyanin (HA) / kg body weight of rats (N+HA); Group III: Diabetic control (D); Group IV: Diabetic rats given 50 mg Hibiscus anthocyanin $(H A) / k g$ body weight of rats (D+HA); V: Diabetic rats given $150 \mathrm{mg}$ metformin/kg body weight of rats (D+M). 'a' indicates values significantly differ from normal control groups. ' $b$ ' indicates values significantly different from diabetic groups. ' $c$ ' indicates values are significantly different from HA treated groups. Significance accepted at $p<0.05$.

Reduced Glutathione content (GSH) in liver: The of GSH in diabetic control rats compared to the concentration of hepatic non-enzymatic antioxidantreduced glutathione (GSH) has shown in figure 6. A normal control rats. In contrast, GSH concentration significant decline was observed in the concentration was significantly enhanced after treatment with $\mathrm{HA}$ or metformin in the liver of diabetic rats.

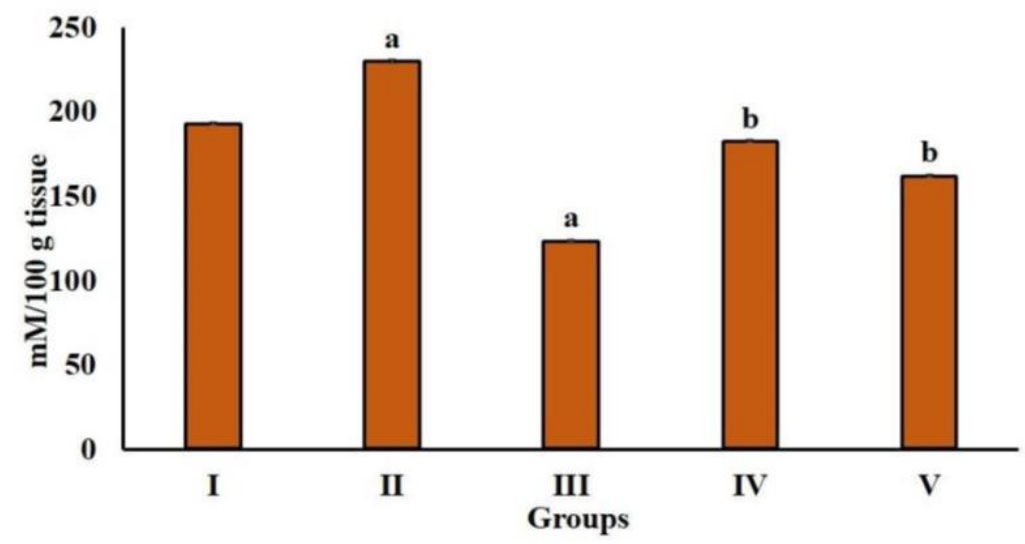

Figure 6. Reduced Glutathione content (GSH) in liver

Values are presented as mean \pm SD $(n=6)$. Group I: Normal control(N); Group II: Normal rats given 50 mg Hibiscus anthocyanin (HA) / kg body weight of rats (N+HA); Group III: Diabetic control (D); Group IV: Diabetic rats given 50 mg Hibiscus anthocyanin $(H A) / k g$ body weight of rats $(D+H A) ; V$ : Diabetic rats given $150 \mathrm{mg}$ metformin/kg body weight of rats (D+M). 'a' indicates values significantly different from normal control groups. 'b' indicates values significantly different from diabetic groups. Significance accepted at $p<0.05$. 
Lipid peroxidation products in the liver: The levels of lipid peroxidation products, Thiobarbituric acidreactive substances (TBARS), hydroperoxides (HP), and conjugated dienes $(C D)$ in the liver of normal and experimental animals were shown in table 3. A significant elevation was observed in the levels of
TBARS, HP, and CD in the liver of diabetic control rats as compared to normal control rats. Diabetic rats treated with HA or metformin showed a significant reduction in the levels of lipid peroxidation products compared to diabetic control groups (Table 3).

Table 3: Lipid peroxidation products in the liver

\begin{tabular}{|c|c|c|c|}
\hline GROUPS & TBARS (mM/100 g tissue) & CD (mM/100 g tissue) & HP (mM/100 g tissue) \\
\hline I & $1.57 \pm 0.149$ & $27.8 \pm 2.66$ & $53.48 \pm 5.12$ \\
\hline II & $1.44 \pm 0.134$ & $23.1 \pm 2.22^{\mathrm{a}}$ & $41.50 \pm 3.97^{\mathrm{a}}$ \\
\hline III & $2.75 \pm 0.260^{\mathrm{a}}$ & $45.0 \pm 4.35^{\mathrm{a}}$ & $50.86 \pm 8.7^{\mathrm{a}}$ \\
\hline IV & $1.82 \pm 0.175^{\mathrm{b}}$ & $31.6 \pm 3.04^{\mathrm{b}}$ & $5.61^{\mathrm{b}}$ \\
\hline V & $1.87 \pm 0.80^{\mathrm{b}}$ & $35.3 \pm 3.41^{\mathrm{b}}$ & $63.36 \pm 6.09^{\mathrm{b}}$ \\
\hline
\end{tabular}

Values are expressed as mean \pm SD $(n=6)$. Group I: Normal control(N); Group II: Normal rats given 50 mg Hibiscus anthocyanin (HA) /kg body weight of rats (N+HA); Group III: Diabetic control (D); Group IV: Diabetic rats given 50 mg Hibiscus anthocyanin $(H A) / k g$ body weight of rats $(D+H A) ; V$ : Diabetic rats given $150 \mathrm{mg}$ metformin/kg body weight of rats $(D+M)$. 'a' indicates values significantly different from normal control groups. 'b' indicates values significantly different from diabetic groups. Significance accepted at $p<0.05$

\section{DISCUSSION}

Hyperglycemia triggers oxidative stress and reduces the antioxidant defense mechanism by generating advanced glycation end products. (AGEs). As oxidative stress perturbs the antioxidant defense system, it plays a critical role in diabetes complications [29]. In the current study, we identified that the anthocyanins present in the Hibiscus rosa sinensis flower petals could attenuate hyperglycemiainduced hepatic injury by mitigating oxidative stress. The reduction in body weight associated with diabetes is caused by dehydration, carbohydrate loss, and the excessive breakdown of fats and proteins in tissues [30]. The results of our study corroborate this; body weights were significantly diminished in STZinduced diabetic rats. The oral administration of HA or metformin to diabetic rats for 30 days significantly improved the body weight, which indicated the efficacy of Hibiscus anthocyanins in maintaining better glycemic control in diabetic rats.

Streptozotocin is one of the diabetogenic substances used to induce diabetes mellitus in experimental animals. The intraperitoneal injection of STZ partially damages the insulin-secreting pancreatic beta cells by breaking the DNA strand, resulting in decreased insulin biosynthesis and secretion [31-32]. The impairment in the synthesis of 
insulin leads to persistent hyperglycemia [33-34]. In the present study, the blood glucose level was significantly elevated in diabetic control rats. However, treatment with HA or metformin significantly reduced the blood glucose level in diabetic rats, which suggests that Hibiscus anthocyanins protect the pancreatic $\beta$-cells against hyperglycemia-induced oxidative stress and could also preserve their functionality and insulin release. This result agrees with the previous studies that showed the protective role of flavonoid-rich ethyl acetate fraction of Hibiscus rosa sinensis petals in insulin secretion in $\beta$-cells under high glucose conditions in RIN-m5F cells [35].

Glycosylated hemoglobin ( $\mathrm{HbA} 1 \mathrm{c})$ is a useful marker to assess the risk of diabetes mellitus. HbA1c is formed from the non-enzymatic and irreversible covalent bonding of glucose with $\mathrm{Hb}$ in circulation. The increase in $\mathrm{HbA} 1 \mathrm{c}$ in diabetic patients is directly proportional to fasting blood glucose [36]. Similar to previous reports, we found that diabetic control rats had a significantly higher level of $\mathrm{HbA1c}$. In contrast, rats that were treated with HA or metformin showed significant declines in $\mathrm{HbA1c}$. The reduction in the level of $\mathrm{HbA} 1 \mathrm{c}$ in $\mathrm{HA}$-treated diabetic rats indicated the anti-hyperglycemic effect of Hibiscus anthocyanins by ameliorating glycemic control.

Hepatic marker enzymes (Alanine aminotransferase and Aspartate aminotransferase) elevated in the bloodstream indicate hepatocellular damage as these enzymes appear to have leaked from the liver into the bloodstream. [37]. Consistent with the previous reports, our results showed the activities of AST and ALT were significantly higher in diabetic control rats. However, the oral administration of $\mathrm{HA}$ or metformin significantly reduced the activities of AST and ALT in diabetic rats.
The activities of toxicity markers were not altered in normal rats administered with $\mathrm{HA}$, indicating the nontoxic nature of $\mathrm{HA}$ in normal conditions. These findings revealed the hepatoprotective nature of Hibiscus anthocyanins extract. Earlier studies have reported that anthocyanin-rich black rice extract protects against alcohol-induced liver damage in rats [38].

Hyperlipidemia is one of the major risk factors for cardiovascular disease in type 2 diabetes. The characteristic features of diabetic dyslipidemia include elevated plasma concentrations of triglycerides and apo B-containing lipoproteins, low HDL cholesterol, and increased concentrations of small, dense LDL-cholesterol particles [39]. Consistent with the previous reports, in the present study, diabetic rats exhibited a significant elevation of TC, TG, and LDL-C while decreasing HDL-C. Hibiscus anthocyanins or metformin administration lowered TC, TG, and LDL-C levels with an elevation of HDL-C level. A decline in serum lipid profiles observed in hibiscus anthocyanin administered diabetic rats suggests that its potential to regulate hyperlipidemia in the diabetic condition is mediated by the elevation of insulin level.

The increased production of ROS in hyperglycemia causes lipid peroxidation and tissue damage. The essential enzymatic antioxidants are superoxide dismutase (SOD), catalase (CAT), glutathione peroxidase (GPx), and glutathione reductase (GRd). Reduced glutathione (GSH) is a nonenzymatic antioxidant employed in free radical defense systems to remove radicals and protect biological sites [40]. SOD reduces superoxide radicals to hydrogen peroxide $\left(\mathrm{H}_{2} \mathrm{O}_{2}\right)$, and catalase reduces hydrogen peroxide to water and protects tissues from reactive hydroxyl radicals [41]. The activities of the 
enzymatic and non-enzymatic antioxidant systems are depleted during oxidative stress [42]. In the current study, there was a decline in the activities of antioxidants enzymes SOD, CAT, GPx and, GRd in the liver of diabetic control rats. Treatment with HA and Metformin in diabetic rats enhanced antioxidant enzymes SOD, CAT, GPx and, GRd in the liver of diabetic rats. These results suggest that Hibiscus anthocyanins extract could improve the activities of enzymatic antioxidants, reduce free radicals, and alleviate liver damage caused by oxidative stress in diabetic rats. Our results are consistent with other studies showing that an anthocyanin-rich ethanolic extract of Vaccinium Arctostaphylos fruit increases antioxidant markers in alloxan-induced diabetic rats. [43].

Glutathione (GSH) is a tripeptide ( $\gamma$ - glutamyl cysteinyl glycine) and a non-enzymatic antioxidant molecule. It is critical for cellular protection, such as detoxification of ROS, conjugation, excretion of toxic molecules, and controlling the release of inflammatory cytokines [44]. In previous studies, GSH concentration was found to decline in diabetic rats [45]. In the present study, supplementation of HA and Metformin significantly increased GSH levels in diabetic rats. We found that Hibiscus anthocyanins extract protected the liver from oxidative damage by stimulating GSH synthesis.

Oxidative processes, glucose homeostasis, and detoxification of major metabolites produced by excessive reactive oxygen species are all vital functions of the liver [46]. Lipid peroxidation is an important biomarker of free radical-mediated oxidative stress. During this process, free radicals interact with polyunsaturated fatty acids (PUFAs), leading to the formation of malondialdehyde (MDA) and 4-hydroxynonenal, which cause adverse effects such as cell necrosis and inflammation [47]. Increased lipid peroxidation induces disturbance of membrane organization, functional loss, modification of the protein, and DNA bases [48]. Diabetic rats have been shown to have elevated levels of lipid peroxidative markers (TBARS, HP, and CD) in the liver [49]. TBARS, $H P$, and $C D$ were significantly elevated in the livers of diabetic control rats in the present study. Metformin and HA supplementation reduced TBARS, HP, and CD in the liver of diabetic rats. Hibiscus anthocyanins extract shows hepatoprotective properties against STZ induced hepatic injury by suppressing lipid peroxidation and restoring endogenous antioxidants. Results of the current study are consistent with previous studies showing that anthocyanin-rich mulberry extract inhibits oxidative stress induced by hyperglycemia by regulating the AMPK/ACC/mTOR pathway [50].

\section{CONCLUSION}

In conclusion, the present study showed that Hibiscus anthocyanins (50mg/kg body weight) extract might provide effective protection against oxidative stress damage in the liver of STZ induced diabetic rats. Hibiscus anthocyanins may reduce lipid peroxidation and free radical levels in hepatic tissues as well as increase enzymatic and non-enzymatic antioxidant defense. Results from this study suggest that anthocyanin fraction of Hibiscus rosa sinensis flower petals may be effective against hepatic complications associated with DM. This study confirmed that supplementation of anthocyanins present in the Hibiscus rosa sinensis flower petals could significantly modulate the complications associated with hyperglycemia by modulating oxidative stress and 
regulating antioxidant enzymes and afford protection against hepatic damage.

List of abbreviations: CAT: Catalase, CD: Conjugated dienes, DM: Diabetes Mellitus, GPx: Glutathione Peroxidase, GRd: Glutathione Reductase, GSH: Reduced Glutathione, HA: Hibiscus rosa sinensis flower anthocyanin, HbA1c: Glycosylated Hemoglobin, HDL-C: High-density Lipoprotein cholesterol, HP: Hydroperoxides, LDL-C: Low-density Lipoprotein cholesterol, ROS: Reactive oxygen species, SGOT: Serum Glutamate Oxaloacetate Transaminase, SGPT: Serum Glutamate Pyruvate Transaminase, SOD: Superoxide dismutase, STZ: Streptozotocin, TBARS: Thiobarbituric acid reactive substances

Authors' contribution: The original idea was conceived by V S Kalpana, Jincy Mary, and S Mini. This was discussed with N P Soumya and Sukanta Mondal.

\section{REFERENCES}

1. Ozougwu JC, Obimba KC, Belonwu CD, Unakalamba CB. The pathogenesis and pathophysiology of type 1 and type 2 diabetes mellitus. Journal of physiology and pathophysiology 2013, 4(4):46-57. https://doi.org/10.5897/JPAP2013.0001

2. Valko M, Leibfritz D, Moncol J, Cronin MT, Mazur M, Telser J. Free radicals and antioxidants in normal physiological functions and human disease. The international journal of biochemistry and cell biology 2007, 39(1):44-84.

DOI: https://doi.org/10.1016/j.biocel.2006.07.001

3. Yaribeygi H, Mohammadi MT, Sahebkar A. Crocin potentiates antioxidant defense system and improves oxidative damage in liver tissue in diabetic rats. Biomedicine and Pharmacotherapy 2018, 98:333-337. DOI: https://doi.org/10.1016/j.biopha.2017.12.077
The main focus and ideas of the paper were finally agreed upon by all authors. The experiments were conducted and analyzed by V S Kalpana and Jincy Mary. S Mini conceptualized the main ideas behind the experiments. The main text of the paper was written by $\mathrm{V} S$ Kalpana and S Mini. The manuscript was revised and edited by S Mini and N P Soumya, with Sukanta Mondal contributing to the editing and writing parts. All authors contributed to the writing and editing of the final draft.

Conflicts of Interest: We wish to declare that there are no conflicts of interest associated with this study.

Acknowledgements: The financial assistance from Kerala State Council for Science, Technology, and Environment (KSCSTE) Research fellowship (No 001/ FSHP- MAIN /2015), Thiruvananthapuram, Kerala, and the facilities provided by the University of Kerala are greatly acknowledged.

4. Cichoż-Lach H, Michalak A. Oxidative stress as a crucial factor in liver diseases. World journal of gastroenterology: WJG 2014, 20(25):8082. DOI: https://doi.org/10.3748/wjg.v20.i25.8082

5. Cui H, Kong $\mathrm{Y}$, Zhang $\mathrm{H}$. Oxidative stress, mitochondrial dysfunction, and aging. Journal of signal transduction 2012. DOI: https://doi.org/10.1155/2012/646354

6. Ugochukwu NH, Babady NE. Antioxidant effects of Gongronema latifolium in hepatocytes of rat models of non-insulin dependent diabetes mellitus Fitoterapia 2002, 73(7-8):612-618. DOI: https://doi.org/10.1016/s0367-326x(02)00218-6

7. Abbas ZK, Saggu S, Sakeran MI, Zidan N, Rehman H, Ansari AA. Phytochemical, antioxidant and mineral composition of hydroalcoholic extract of chicory (Cichorium intybus L.) leaves. Saudi journal of biological sciences 2015, 22(3):322-326. DOI: https://doi.org/10.1016/j.sjbs.2014.11.015 
8. Jadhav VM, Thorat RM, Kadam VJ, Sathe NS. Traditional medicinal uses of Hibiscus rosa-sinensis. J Pharm Res 2009, 2(8):1220-1222.

9. Pillai SS, Mini S. Hibiscus rosa sinensis Linn. petals modulates glycogen metabolism and glucose homeostasis signalling pathway in streptozotocininduced experimental diabetes. Plant foods for human nutrition 2016, 71(1):42-48.

\section{DOI: https://doi.org/10.1007/s11130-015-0521-6}

10. Bunea A, Rugină D, Sconţa Z, Pop RM, Pintea A, Socaciu C, Tăbăran F, Grootaert C, Struijs K, VanCamp J. Anthocyanin determination in blueberry extracts from various cultivars and their antiproliferative and apoptotic properties in B16-F10 metastatic murine melanoma cells. Phytochemistry 2013, 95:436-444. DOI: https://doi.org/10.1016/j.phytochem.2013.06.018

11. Gowd V, Bao T, Chen W. Antioxidant potential and phenolic profile of blackberry anthocyanin extract followed by human gut microbiota fermentation. Food research international 2019, 120:523-533. DOI: https://doi.org/10.1016/j.foodres.2018.11.001

12. Fallah AA, Sarmast E, Jafari T. Effect of dietary anthocyanins on biomarkers of oxidative stress and antioxidative capacity: A systematic review and metaanalysis of randomized controlled trials. Journal of Functional Foods 2020, 68:103912. https://doi.org/10.1016/j.jff.2020.103912

13. Parthasarathi S, Ezhilarasi PN, Jena BS, Anandharamakrishnan C. A comparative study on conventional and microwave-assisted extraction for microencapsulation of Garcinia fruit extract. Food and Bioproducts Processing 2013, (2):103-110. DOI: https://doi.org/10.1016/j.fbp.2012.10.004

14. Wedick NM, Pan A, Cassidy A, Rimm EB, Sampson L, Rosner B, Willett W, Hu FB, Sun Q, van Dam RM. Dietary flavonoid intakes and risk of type 2 diabetes in US men and women. The American journal of clinical nutrition 2012, (4):925-933.

DOI: https://doi.org/10.3945/ajcn.111.028894

15. Longo L, Scardino A, Vasapollo G. Identification and quantification of anthocyanins in the berries of Pistacia lentiscus L., Phillyrea latifolia L. and Rubia peregrina L. Innovative Food Science and Emerging Technologies $2007,8(3): 360-364$.

DOI: https://doi.org/10.1016/j.ifset.2007.03.010
16. Rapisarda P, Fanella F, Maccarone E. Reliability of analytical methods for determining anthocyanins in blood orange juices. Journal of Agricultural and Food Chemistry 2000, 48(6):2249-2252. DOI: https://doi.org/10.1021/jf991157h

17. Pazmiño-Durán EA, Giusti MM, Wrolstad RE, Glória MB. Anthocyanins from Oxalis triangularis as potential food colorants. Food Chemistry 2001, 75(2):211-216. DOI: https://doi.org/10.1016/S0308-8146(01)00201-1

18. Ramesh B, Pugalendi KV. Antihyperglycemic effect of umbelliferone in streptozotocin-diabetic rats. Journal of medicinal food 2006, (4):562-566.

DOI: https://doi.org/10.1089/jmf.2006.9.562

19. Huggett AS, Nixoh DA. Use of glucose oxidase, peroxidase, and O-dianisidine in determination of blood and urinary glucose. Lancet 1957, 273:368-370. DOI: https://doi.org/10.1016/s0140-6736(57)92595-3

20. Reitman S, Frankel S. A colorimetric method for the determination of serum glutamic oxalacetic and glutamic pyruvic transaminases. American journal of clinical pathology. 1957, (1):56-63. DOI: https://doi.org/10.1093/ajcp/28.1.56

21. Maehly AC, Chance B. Methods of biochemical analysis. by Glick D., Interscience, New York. 1954:454. DOI: https://doi.org/10.1002/9780470110171.ch14

22. Kakkar P, Das B, Viswanathan PN. A modified spectrophotometric assay of superoxide dismutase.

23. Agergaard N, Jensen PT. Procedure for blood glutathione peroxidase determination in cattle and swine. Acta Veterinaria Scandinavica. 1982, (4):515527. DOI: https://doi.org/10.1186/BF03546770

24. Hovatta I, Tennant RS, Helton R, Marr RA, Singer O, Redwine JM, Ellison JA, Schadt EE, Verma IM, Lockhart DJ, Barlow C. Glyoxalase 1 and glutathione reductase 1 regulate anxiety in mice. Nature 2005, (7068):662-666. DOI: https://doi.org/10.1038/nature04250

25. Patterson JW. Determination of glutathione. Methods Biochem Anal 1955, 2:259-278. DOI: https://doi.org/10.1002/9780470110188.ch9

26. Okhawa $\mathrm{H}$, Ohishi N, Yagi K. Reaction of linoleic acid hydroperoxides with thiobarbituric acids. Anal Biochem 1979, 95(2):351-354. DOI: https://doi.org/10.1016/0003-2697(79)90738-3 
27. Buege JA, Aust SD. Microsomal lipid peroxidation. In Methods in enzymology 1978, 52:302-310. Academic press. DOI: https://doi.org/10.1016/s0076-6879(78)52032-6

28. Lowry OH, Rosebrough NJ, Farr AL, Randall RJ. Protein measurement with the Folin phenol reagent. Journal of biological chemistry 1951, 193:265-75. https://doi.org/10.1016/S0021-9258(19)52451-6

29. Muruganathan $U$, Srinivasan $S$. Beneficial effect of carvone, a dietary monoterpene ameliorates hyperglycemia by regulating the key enzymes activities of carbohydrate metabolism in streptozotocin-induced diabetic rats. Biomedicine and Pharmacotherapy 2016, 84:1558-1567. DOI: https://doi.org/10.1016/j.biopha.2016.11.025

30. Srinivasan S, Muruganathan U. Antidiabetic efficacy of citronellol, a citrus monoterpene by ameliorating the hepatic key enzymes of carbohydrate metabolism in streptozotocin-induced diabetic rats. Chemicobiological interactions 2016, 250:38-46. DOI: https://doi.org/10.1016/j.cbi.2016.02.020

31. Kim MJ, Ryu GR, Chung JS, Sim SS, Min DS, Rhie DJ, Yoon SH, Hahn SJ, Kim MS, Jo YH. Protective Effects of Epicatechin against the Toxic Effects of Streptozotocin on Rat Pancreatic Islets: in vivo and in vitro. Korean Journal of Physiology and Pharmacology 2002, 6:67-70. DOI: https://doi.org/10.1097/00006676-200304000$\underline{00014}$

32. Murali R, Srinivasan $\mathrm{S}$, Ashokkumar $\mathrm{N}$. Antihyperglycemic effect of fraxetin on hepatic key enzymes of carbohydrate metabolism in streptozotocin-induced diabetic rats. Biochimie 2013, 95(10):1848-1854.

DOI: https://doi.org/10.1016/j.biochi.2013.06.013

33. Sundaram R, Naresh R, Shanthi $P$, Sachdanandam $P$. Efficacy of 20-OH-ecdysone on hepatic key enzymes of carbohydrate metabolism in streptozotocin induced diabetic rats. Phytomedicine 2012,19(8-9):725-729. DOI: https://doi.org/10.1016/j.phymed.2012.02.019

34. Saini V. Molecular mechanisms of insulin resistance in type 2 diabetes mellitus. World journal of diabetes 2010, 1(3):68. DOI: https://doi.org/10.4239/wjd.v1.i3.68

35. Pillai, Sneha S., and S. Mini. Attenuation of high glucose induced apoptotic and inflammatory signaling pathways in RIN-m5F pancreatic $\beta$ cell lines by Hibiscus rosa sinensis L. petals and its phytoconstituents. Journal of ethnopharmacology 2018, 8-17.

DOI: https://doi.org/10.1016/j.jep.2018.08.022

36. Edelman D, Olsen MK, Dudley TK, Harris AC, Oddone EZ. Utility of hemoglobin $A 1 \mathrm{c}$ in predicting diabetes risk. Journal of general internal medicine 2004, 19(12):11751180.

DOI: https://doi.org/10.1111/i.1525-

1497.2004.40178.x

37. Ashokkumar N, Pari L. Effect of N-benzoyl-Dphenylalanine and metformin on carbohydrate metabolic enzymes in neonatal streptozotocin diabetic rats. Clinica chimica acta 2005, 351(1-2):105-113.

DOI: https://doi.org/10.1016/j.cccn.2004.08.011

38. Hou Z, Qin P, Ren G. Effect of anthocyanin-rich extract from black rice (Oryza sativa L. Japonica) on chronically alcohol-induced liver damage in rats. Journal of agricultural and food chemistry 2010, 58(5):3191-3196. DOI: https://doi.org/10.1021/jf904407x

39. Mooradian AD. Dyslipidemia in type 2 diabetes mellitus. Nature Reviews Endocrinology 2009, 5(3):150-159. DOI: https://doi.org/10.1038/ncpendmet1066

40. Ighodaro OM, Akinloye OA. First line defence antioxidants-superoxide dismutase (SOD), catalase (CAT) and glutathione peroxidase (GPX): Their fundamental role in the entire antioxidant defence grid. Alexandria journal of medicine 2018, 54(4):287-293. https://doi.org/10.1016/i.ajme.2017.09.001

41. Sözmen EY, Sözmen $B$, Delen $Y$, Onat $T$. Catalase/superoxide dismutase (SOD) and catalase/paraoxonase (PON) ratios may implicate poor glycemic control. Archives of medical research 2001, 32(4):283-287.

\section{DOI: https://doi.org/10.1016/s0188-4409(01)00285-5}

42. Maritim AC, Sanders A, Watkins lii JB. Diabetes, oxidative stress, and antioxidants: a review. Journal of biochemical and molecular toxicology 2003,17(1):2438.

DOI: https://doi.org/10.1002/jbt.10058

43. Feshani AM, Kouhsari SM, Mohammadi S. Vaccinium arctostaphylos, a common herbal medicine in Iran: Molecular and biochemical study of its antidiabetic effects on alloxan-diabetic Wistar rats. Journal of ethnopharmacology 2011, 133(1):67-74. 
DOI: https://doi.org/10.1016/j.jep.2010.09.002

44. Brown LA, Harris FL, Ping XD, Gauthier TW. Chronic ethanol ingestion and the risk of acute lung injury: a role for glutathione availability? Alcohol 2004, 33(3):191197. DOI: https://doi.org/10.1016/j.alcohol.2004.08.002

45. Sayed AA. Ferulsinaic acid modulates SOD, GSH, and antioxidant enzymes in diabetic kidney. Evidence-Based Complementary and Alternative Medicine 2012. DOI: https://doi.org/10.1155/2012/580104

46. Kapoor R, Kakkar P. Naringenin accords hepatoprotection from streptozotocin induced diabetes in vivo by modulating mitochondrial dysfunction and apoptotic signaling cascade. Toxicology reports 2014, 1:569-581. DOI: https://doi.org/10.1016/j.toxrep.2014.08.002

47. Ayala $A$, Muñoz MF, Argüelles S. Lipid peroxidation: production, metabolism, and signaling mechanisms of malondialdehyde and 4-hydroxy-2-nonenal. Oxidative medicine and cellular longevity 2014. DOI: https://doi.org/10.1155/2014/360438

48. Niki E. Lipid peroxidation: physiological levels and dual biological effects. Free Radical Biology and Medicine 2009, (5):469-484. DOI: https://doi.org/10.1016/j.freeradbiomed.2009.05.032

49. Roy S, Sehgal R, Padhy BM, Kumar VL. Antioxidant and protective effect of latex of Calotropis procera against alloxan-induced diabetes in rats. Journal of Ethnopharmacology 2005, 102(3):470-473.

DOI: https://doi.org/10.1016/j.jep.2005.06.026

50. Yan F, Zheng X. Anthocyanin-rich mulberry fruit improves insulin resistance and protects hepatocytes against oxidative stress during hyperglycemia by regulating $A M P K / A C C / m T O R$ pathway. Journal of Functional Foods 2017, 30:270-281.

https://doi.org/10.1016/j.jff.2017.01.027 